\title{
Adopting the system of rice intensification (SRI) in Tanzania: A review
}

\author{
Zacharia Katambara ${ }^{1 *}$, Frederick C. Kahimba², Henry F. Mahoo ${ }^{2}$, Winfred B. Mbungu², \\ Fikiri Mhenga ${ }^{2}$, Paul Reuben ${ }^{2}$, Muyenjwa Maugo ${ }^{3}$, Anthony Nyarubamba ${ }^{3}$ \\ ${ }^{1}$ Department of Civil Engineering, Mbeya University of Science and Technology, Mbeya, Tanzania; \\ *Corresponding Author: zacharia.katambara@mist.ac.tz, zkatambara1@gmail.com \\ ${ }^{2}$ Department of Agricultural Engineering and Land Planning, Sokoine University of Agriculture, Morogoro, Tanzania \\ ${ }^{3}$ Directorate of Irrigation, Ministry of Agriculture, Food Security, and Cooperatives, Morogoro, Tanzania
}

Received 2 June 2013; revised 2 July 2013; accepted 20 July 2013

Copyright (C) 2013 Zacharia Katambara et al. This is an open access article distributed under the Creative Commons Attribution License, which permits unrestricted use, distribution, and reproduction in any medium, provided the original work is properly cited.

\section{ABSTRACT}

The demand of water for irrigation purposes in Tanzania outstrips the amount of water available for irrigation and other demands. On the other hand, the demand for more food to feed the growing population is increasing, calling for the need to have technologies and farming practices that ensure more food production while minimizing water uses. Rice is among cereal crops grown in Tanzania, and it can assist in meeting the food demand for the nation. Majority of rice producers in Tanzania and Sub-Saharan Africa (SSA) are subsistence farmers and they practice continuous flooding, a technique that requires much water. In addition to using large amounts of water, the conventional practices of growing paddy using local varieties transplanting process are implemented when seedlings are more than 21 days old, and 3 - 4 seedlings are transplanted in one hole. This practice results in low yields, and low water productivity and water use efficiency. The system of rice intensification (SRI) on the other hand, is a promising new practice of growing paddy rice that has proven to be very effective in saving water and increasing rice yields in many parts of the world. SRI practice is spreading fast and it has been adopted in many countries. The SRI practice has been introduced in Tanzania during the last 3 years as such it is not widely practiced. This paper reviews SRI practice at global, regional and country (Tanzania) level, and evaluates the challenges, opportunities and implications for its adoption in Tanzania. Knowledge gaps at each level have been identified and dis- cussed as well as suggestions for researchable areas.

Keywords: System of Rice Intensification; Rice Production; Paddy; Alternate Wetting and Drying

\section{INTRODUCTION}

The human population in many regions in the world is generally increasing, and is increasing in an unexpected manner. For instance, the 2012 population datasheet produced by the Population Reference Bureau indicated that the population will continue to increase at a higher rate in developing countries than developed countries [1]. In Tanzania the average population growth rate is more than $3.0 \%$. Developing countries are characterised by low incomes, high economic vulnerability, and poor human development indicators [1]. On the other hand, the demand for domestic water requirements and food to feed the growing population is increasing and is contrary to the current food production capacity. In countries like China and South Africa, the grain production is mainly from irrigation. China is experiencing a sudden decline in irrigation water supply [2]. In South Africa, the water resources are fully developed to an extent that irrigators are required to operate below their production capacity during dry periods [3]. For a developing country like Tanzania, the food consumed in major cities is produced by subsistence farmers whose yields are low and the whole growing period is vulnerable to climate change. It is therefore imperative to embark on technologies and farming practices that ensure more food production while using less water.

Rice is among the most popular cereal crops grown in many regions of Tanzania and Sub-Saharan Africa (SSA). In Tanzania paddy rice is grown by subsistence farmers 
who practice conventional approach of continuous flooding, a technique that requires large amounts of water. These agronomic practises have been noted to lead to lower water productivity of less than $0.3 \mathrm{~kg} / \mathrm{m}^{3}$ (Mdemu et al., 2004). In addition, $70 \%$ of subsistence farmers in Usangu Plain in Tanzania for example, have limited access to the highly needed water resource for irrigation as well as for maintaining the ecosystem in the Ruaha National Park and beyond [4]. The combination of high demand for food, inadequate irrigation and domestic water requirements, as well as the effects that climate change and variability have on the food production processes calls for appropriate water saving technologies as adaptation measures. The technologies to be considered should be those that result in low water consumption while producing higher yields that increase food security, and technologies that can easily be implemented by subsistence farmers. These approaches include the system of rice intensification (SRI). Hence, the main objective of this review was to document the adoption of SRI in Tanzania, and evaluate its performance and acceptability under local Tanzanian conditions.

\section{HISTORICAL BACKGROUND OF SRI}

\subsection{Overview and Origin of SRI}

Although higher yields of paddy can be obtained under irrigated rice production systems, large investments in the form of equipment and external inputs requirement of irrigation infrastructure is a challenge to subsistence rice producers. It is from these inabilities to afford the expensive inputs that made Father Henri de Laulanie, a French Jesuit priest, to serendipitously experiment by transplanting 15 days old seedling in 1983 in Madagascar. The yields obtained ranged from 7 to $15 \mathrm{t} / \mathrm{ha}$ [5]. This practice was thereafter called system of rice intensification (SRI) and it provided evidence on appropriate synergiesthat result from a set of principles and bio-physical mechanismsthat can positively alter the known agronomic yield ceilings when optimally implemented.

From the subsistence farmer's perspective, SRI can be defined as the use of the existing assets differently and yet increasing the yield and reducing water use while producing healthy and quality grains with strong aroma. With all the advantages associated with SRI, it lacks proper guidelines and it is considered to be highly empirical. Agricultural scientists have shown interest on attempts to improve scientific knowledge on SRI [5], so as to produce guidelines on the practices and principles applicable in various regions [6,7]. On the other hand, SRI is regarded as a standard package of specific practices that significantly reflect local conditions [8] based on the bio-physical mechanisms within agro-ecological environments [5]. It is imperative to have on-farm par- ticipatory action research (PAR) under defined farmingsystems approach so as to validate the practical relevance and risks associated with practicing SRI under specific local conditions.

\subsection{Principles of SRI}

The SRI practice consists of applied principles ranging from seed sorting, sowing, transplanting younger seedlings, weeding, and water management, all within the growing period of rice plants. A brief explanation of the principles is given below [5]:

- Sorting out of the seeds: Although other approaches used in sorting rice seed may exist, in SRI the approach used to remove defective seeds from good seeds so as to ensure that only good seeds are sown is by flotation-sink method in salty solution. Good seeds are the ones that sink in salty water capable of floating a rawegg. Generally the concentration is not substantial to cause an effect on the selected seed.

- Raising seedlings in garden like nursery: This ensures a careful management of seedlings and easy uprooting as well as transplanting.

- Uprooting and transplanting time: The time between uprooting and transplanting should be between 15 30 minutes and the roots should be kept moist during this time [5].

- Early transplanting of 8 to 15 days old seedlings: In addition to the provision of adequate buffer for the seedling from being damaged during transplanting, full tillering and optimal production occurs when the seedling are transplanted before entering the fourth phyllochron of growth [5].

- Single, widely spaced transplants: This ensures that the plants have enough space for tillering as well as to allow a mechanical weeder to pass through without harming the plants.

- Early and regular weeding: This ensures that weeds do not compete with the rice plant. In addition, mechanical weeders aerate the soil. The roots need oxygen so as to be strong and healthy for optimal tillering and development of healthy rice grains.

- Carefully controlled water management: Makes the rice plant healthy since the roots are supplied with moisture as well as air. This allows the rootto uptake adequate nutrients from various soil horizons.

- Application of compost: The compost materials are rich with nutrients as well as organisms whose activeties favour the growth of rice. Above all it is environmentally friendly to use composite than industrial fertilizers.

- No use of herbicides: The non-use of herbicides favours the sustainability of the ecosystem and the micro-organisms whose activities are suitable for the growth of rice plants. 
However, the quantitative parameters such as plant spacing, age of transplanting, minimum moisture content, and alternate wetting and drying depend on soil characteristics and moisture content of a given area, necessitating the need for research to customize the parameters for a particular region.

\subsection{Comparison of SRI with Other Rice Growing Practices}

Rice growing practices can be classified as conventional or non-conventional. Conventional practices involve application of chemical fertilizers, pesticides, herbicides, as well as flooding the fields; while non-conventional practices like SRI does not [9]. Flooding involves damming and channelling of water so as to suppress growth of weeds that cannot tolerate aquatic nature [10]. Considering the fact that in the coming 30 years approximately $80 \%$ of additional food supply will have to be produced on irrigated land [11], more farm inputs and limited irrigation water available as well as lower farm gates price [9] will continue to limit the prospects of subsistence farmers in developing countries. On the other hand, SRI uses less water and it requires less farm inputs than the conventional rice growing practice. Hence if adopted by rice growers in Tanzania SRI will help to increase rice yields and food self-sufficiency, hence improve the livelihood of subsistence rice farmers in Tanzania.

\subsection{Water Use and Yield under Conventional Rice Growing Practices}

The International Rice Research Institute (IRRI) categorised five rice growing regimes as: water regime (deficit, excess, or optimum), drainage regime (poor or good), temperatureregime (optimum or low), soils regime (normal or problem), and topography regime (flat or undulating) [12]. Under conventional transplanted rice growing practice, seedbeds are prepared and seeds are then sown in nurseries first. At the age of 21 days or more, two or more seedlings per hole are transplanted into already prepared paddies and flooding water regime is maintained throughout the rice growing period from plating to harvesting. Under this practice about $80 \%$ of fresh water resources used for irrigation is consumed by rice crops grown under continuous flooding. [13,14] found that an average of $9204 \mathrm{~m}^{3} / \mathrm{ha}$ is required for an average yield of $4465 \mathrm{~kg} / \mathrm{ha}$ in India [14]. In Kenya, three rice varieties, Basmati 370, BW 196, and IR 2783-80-1 were compared by [13] and it was found that for continuous flooding the amount of water used was 14,062, 18,475, and $17,548 \mathrm{~m}^{3} / \mathrm{ha}$ for Basmati 370 , BW 196, and IR 2783-80-1, respectively; and the subsequent yields were $5.3,3.9$, and 9.4 ton/ha, respectively. Under continuous flooding, substantial amount of water is required and the type of variety plays an important role as well.

\subsection{Water Use and Yields under SRI Practice}

The SRI practice has been reported to result in higher yields ranging from 6 to 8 ton/ha with subsequent water saving of up to $25 \%$. The practice also produces healthy grains, which weighs up to $100-110 \mathrm{~kg}$ per bag, and it produces quality grains with stronger aroma $[13,15]$. Proportional increase in yield and decrease in water use have also been reported in Madagascar and China. In Madagascar, an equal range of between $25 \%$ and $50 \%$ increase in yields and decrease in water use were reported [16]. A similar trend has been reported in China where both increase in yield and decrease in water use were found to be up to $46 \%$ [17]. In those regards, SRI has more advantages than the conventional approaches in subsistence farmer setup.

\section{A GLOBAL REVIEW ON SRI PRACTICE}

Since its introduction, SRI practice has been widely promoted globally, although the strategy's impacts have been a subject of debate [18]. Conflicting results exist, some reporting that a $20 \%-40 \%$ increase in yield and up to $50 \%$ water savings $[16,19-21]$; while others reported insignificant gains [22]. The variation is likely to be attributed to subjective referencing system. Majority of the famers who practice SRI are subsistence farmers whose potential to embark on high capital is limited and are vulnerable to climate change and climate variability. The variation in yield is attributed to the characteristic of the farms and implementation of the strategies $[8,18]$.

In addition, SRI practice is less resource demanding, which include water for irrigation and seeds [23,24]. During the growing season the rice plants under SRI have been noted to be more robust against extreme weather events, pests, and diseases due to plant vigour and strength [7]. These are among the rea- sons for it being adopted in more than 50 countries world wide including major rice-producers such as India, China, Vietnam, and the Philippines [18].

On the other hand and since it discovery, the dissemination and adoption of SRI has been slow due to the necessity of undergoing training as well as the anticipated effective extension services needed for successful adoption [18]. Development agencies and partners were reluctant to accept SRI due to inexistence of peer-reviewed scientific articles that promote SRI [21]. For instance, the adoption of SRI in Timor was slow until the extension agency and farmers were convinced that the innovation was going to be less costly compared to the conventional 
input-intensive rice cultivation system. Studies conducted in the southern and eastern Asia and other developing countries have indicated that SRI increase yields and water saving [5,16,21,24-26]. In Korea it was found that a $5 \%$ to $15 \%$ decrease in runoff occurred in SRI farms, with a water saving of up to $55.6 \%$ of irrigation water [26]. Generally, SRI's impacts are notable in the following areas: 1) Output per hectare is increased usually by $50 \%$ to $200 \%$ or more [8], 2) since SRI fields are not kept continuously flooded, water requirements are reduced, generally by $25 \%-50 \%, 3$ ) the system does not require purchase of new varieties of seed, chemical fertilizer, or agrochemical inputs, although commercial inputs can be used with SRI methods [27], 4) minimal capital costs make SRI methods more accessible to poor farmers, who do not need to borrow money or go into debt, unlike many other innovations [27], and 5) costs of production are usually reduced, typically by $10 \%-20 \%$. Although these percentages vary according to input-intensity of farmers' current production, the need for more research is still high to evaluate SRI impacts under various local conditions.

\section{SRI PRACTICE IN AFRICA REGION}

SRI in western, northern, and southern Africa was introduced at various periods ranging from year 2000 to 2011. Currently more than 18 countries have introduced SRI to its farmers and the practice has been inspired by various issues. For instance, traditionally in Mali, farmers practice either recessional agriculture or deepwater rice cultivation and the extent of the flooding determines the size of land cultivated; a fact which resulted in low yields of less than one ton per hectare [28,29]. Although introduced in 2006, the Zambian agricultural innovations have been improved since the introduction of SRI. The yields have risen to $11.8 \mathrm{ton} / \mathrm{ha}$ depending on the region applied. With respect to water use a saving of up to $50 \%$ can be realized depending on climatic conditions [30]. The number of days required to wet the fields range between 3 - 6 days in Zambia, while in other climatic conditions it may be different. In order for the rice plant to achieve optimum number of productive tillers, the spacing is supposed to be higher, ranging from $15 \mathrm{~cm}$ to $40 \mathrm{~cm}$ grid. However, the optimum spacing varies and has raised some arguments. The yield is likely to have been influenced by the number of weeding done. For instance, the number of weedings done in Zambia were single, twice, thrice, and fourth times and the respective yields realised were, $7.7,7.4,9.1$, and 11.8 tons/ha, respectively. The age of transplanted seedlings is important to a rice plant and also requires some investigation. Also, the use of organic manure is more preferred, but the type and the composition of the manure it not well understood.
In an attempt to introduce SRI, most of the principles contradict with what was believed to be correct. For instance flooding the paddy fields and transplanting more seedlings per hole was conceived to lead to higher yields. This conventional practice is contrary to what SRI does and hence it requires some investigation. Each famer needs to be more observant and adjust the practices so as to make the rice plant reach its full potential. Therefore, appropriate training of extension officers who will thereafter work hand in hand with farmers is required.

\section{A REVIEW OF SRI PRACTICE IN TANZANIA}

\subsection{Background of SRI Practice in Tanzania}

In Tanzania SRI was introduced in 2006 by Kilombero Plantations Limited, a private company in Morogoro which owns 5818 ha of land. The introduction of SRI was a response to the government slogan of "Agriculture First" (Green Revolution), which aimed to support agriculture to increase country's food security. To date several areas have embarked on the SRI practice and they include Mkindo and Dakawa in Morogoro region, and Mwanza and Kilimanjaro Regions. Each of the regions has acquired the technology from either India or Kenya.

Following successes in implementing SRI in various regions, varying results have been observed. Among them include increased grain yields, water use efficiency, number of panicles, and number of productive tillers. In Mkindo area for example, for a spacing of $25 \mathrm{~cm}$ by 25 $\mathrm{cm}$, the grain yield was 6.3 tons/ha, which was higher than conventional practice, which recorded a yield of 3.83 tons/ha [31]. In the same study the above ground biomass obtained was 10.7 tons/ha for SRI compared to 8.9 tons/ha in conventional practice. In addition, other results from the same area indicated that water use under SRI practice was found to be $1.026 \mathrm{~m}^{3} / \mathrm{m}^{2}$ against 2.882 $\mathrm{m}^{3} / \mathrm{m}^{2}$ in conventional practice [31]. This suggests that SRI can save water up to $64 \%$. Also the water productivity obtained range from above 0.29 to $0.47 \mathrm{~kg} / \mathrm{m}^{3}$. This suggests that SRI practices are suitable for water stressed areas in Tanzania.

In addition to the advantages related to yield and water use, SRI has some other advantages which include saving time during transplanting since fewer seedlings are used, planted at a wider spacing. The rice plant stems on SRI are also healthier and robust, hence less susceptible to attack by diseases or pests. The plants remain firm and do not easily fall down during high winds. It is likely that the surface runoff generated from the fields under SRI will be lower than runoff generated in conventional approaches since it reduces the rate of flow. This suggests that SRI can assist to reduce soil erosion from the fields. For conditions of limited agricultural land SRI is capable 
of producing high yields, which increases the food selfsufficiency in the community. In addition, the overall financial saving is achieved from less seeds of up to 10 $\mathrm{kg} / \mathrm{ha}$, and less water use [31].

\subsection{First Season SRI Results from Mkindo Field Experiments in Morogoro, Tanzania}

The current study is experimenting SRI practice in Mkindo irrigation scheme in Morogoro Region. The first season harvest has been done in January 2013. The grain yields observed were $7.35,7.60$, and 9.91 tons/ha for spacings of $35 \mathrm{~cm} \times 35 \mathrm{~cm}, 30 \mathrm{~cm} \times 30 \mathrm{~cm}$, and $25 \mathrm{~cm} \times$ $25 \mathrm{~cm}$, respectively. Although, a spacing of $25 \mathrm{~cm} \times 25$ $\mathrm{cm}$ produced the highest grain yield, chances of having higher yield at lower spacing are there and it calls for further investigation of lower seedling spacing.

\subsection{Knowledge Gaps and Opportunities Associated with SRI Practices}

While worldwide SRI started three decades ago, its knowledge is still evolving and several issues with regard to various components that are involved in its implementation still need some investigation. While there are facts that it can be implemented in any rice growing infrastructure and does not require special infrastructure and high technology, its adoption by smallholder famers in Tanzania is rather slow. Reasons for low rate of adoption of SRI by smallholder farmers under different conditions need to be investigated. In addition, SRI has been reported as a practice that uses less water and produces more. However, its contribution towards resource use efficiency is not well reported and among them includes the land, labour, water, and external inputs and the extent to which it reduces environmental damage associated with many forms of modern conventional rice farming [32].

Production of seeds require healthy grains and with the fact that rice produced under SRI is robust, healthy and is not easily attacked by diseases, the use of SRI practices for generating healthy seeds need to be investigated so as produce healthy seeds for all local rice cultivars to assist subsistence farmers who cannot afford costs of farm inputs and pesticides/herbicides. Erosion and nutrient leaching are associated with excess water in the fields. The use of SRI has been reported to reduce soil erosion and nutrients leaching, but the extent at which this can be achieved is not yet known, and calls for further investigation.

\subsection{Challenges in Implementing SRI}

Despite the advantages associated with SRI, there exist some challenges associated with this practice. They include the need to transplant young seedlings within 20 minutes after uprooting. In a situation where the distance from the seedbed and paddy is far, it is a challenge for the seedlings to be transplanted within 20 minutes. The seeds are vulnerable to rodent and other creatures and therefore pest management is necessary during the rice growing period. With respect to irrigation SRI requires less water, but the assurance on availability of water should be high since it is required when soil moisture in the field is quite low and any delays will significantly affect the rice growing process and hence the yields. Although SRI can easily be integrated into the existing infrastructure, there is a need for a policy framework to support its implementation. Example is the issue of when to irrigate and how to control seepage from neighbouring non-SRI practicing farms that interfere with the drying of the fields.

\section{IMPLICATIONS FOR ADOPTION}

SRI is considered to be among agricultural innovations that attempt to produce more yields while using less farm inputs. Given the nature and varying expectations of the subsistence farmers, appropriate approach towards introduction of SRI is required through the use of experienced researchers and agricultural experts. The design of easily readable training materials to be used during the adoption process is required. In addition, since SRI practice is more practical oriented, practicing farmers may need to have exchange visits to realize what other farmers are experiencing with regard to the implementation of SRI practices. All these require some seed money to be made available during the adoption process. On the other hand, SRI practice has a component of additional weeding since alternate wetting and drying facilitates weed growth, which other practices do not have. But the weed growth indicates that conducive environment exists in farms where SRI is being practised.

\section{CONCLUSIONS AND RECOMMENDATIONS}

This review study was conducted to evaluate the introduction, performance, and acceptability of SRI practices under local Tanzanian conditions. The review has also covered the history and performance of SRI globally and at a regional level. Lessons have been drawn from other parts of the world where SRI practice has been successfully adopted, and recommendations are made on how the practice can be adopted and up-scaled in Tanzania.

Globally, the demand of water for irrigation purposes is increasing and is proportional to demand for food to feed a growing population. Conventional rice farming practices become technically unfavourable in this current 
environment of limited water resources. SRI practices have been reported of using less water, producing high yields and healthy grains which have stronger aroma. In Tanzania research opportunities to develop well elaborative SRI guidelines on suitable transplanting ages, spacing, wetting and drying cycles, and type of manures suitable for SRI practice exist. With the fact that SRI is still evolving, it has not gained a wide spread. In areas where the practice was introduced, it has been positively accepted by subsistence rice growers and has shown positive results. With square gridded transplanting spacing of $25 \mathrm{~cm}$, SRI yield in Mkindo area produced 9.90 tons/ha compared to 3.83 tons/ha in conventional practice, which is $158 \%$ more. The water use was reported to be $1.026 \mathrm{~m}^{3} / \mathrm{m}^{2}$ against $2.882 \mathrm{~m}^{3} / \mathrm{m}^{2}$ in conventional practice, which is less by $35.6 \%$. This provides evidence that when SRI is practiced in water scarce regions like in Tanzania; it can assist to produce more yields while using less water. The high yields walk a long way in ensuring food self-sufficiency, while coping with diminishing water resources under undesirable varying climate. The various components of SRI practice are empirical and site specific, hence more effort is required to ensure that SRI is up-scaled and is widely adopted in Tanzania and beyond.

\section{ACKNOWLEDGEMENTS}

The authors would like to thank the following organisations for the opportunity to carry out this study: Sokoine University of Agriculture, Ministry of Agriculture, Food Security and Cooperatives, Mbeya University of Science and Technology, and SUA Pest Management Centre. The financial support received from the Tanzania Commission of Science and Technology (COSTECH) is highly acknowledged.

\section{REFERENCES}

[1] PRB (2012) 2012 World population datasheet. http://www.prb.org/Publications/Datasheets/2012/world-p opulation-data-sheet.aspx

[2] Brown, L.R. and Halweil, B. (1998) China's water shortage could shake world food security. World Watch, 11, 10-21.

[3] Katambara, Z. and Ndiritu, J. (2009) A fuzzy inference system for modelling stream flow: Case of Letaba River, South Africa. Physics and Chemistry of the Earth, Parts $A / B / C$, 34, 688-700. doi:10.1016/j.pce.2009.06.001

[4] Kadigi, R.M.J., Mdoe, N.S.Y. and Ashimogo, G.C. (2007) Understanding poverty through the eyes of the poor: The case of Usangu Plains in Tanzania. Physics and Chemistry of the Earth, Parts $A / B / C, 32,1330-1338$. doi:10.1016/j.pce.2007.07.029

[5] Stoop, W.A., Uphoff, N. and Kassam, A. (2002) A review of agricultural research issues raised by the system of rice intensification (SRI) from Madagascar: Opportunities for improving farming systems for resource-poor farmers.
Agricultural Systems, 71, 249-274. doi:10.1016/S0308-521X(01)00070-1

[6] Sinha, S.K. and Talati, J. (2007) Productivity impacts of the system of rice intensification (SRI): A case study in West Bengal, India. Agricultural Water Management, 87, 55-60. doi:10.1016/j.agwat.2006.06.009

[7] Stoop, W.A., Adam, A. and Kassam, A. (2009) Comparing rice production systems: A challenge for agronomic research and for the dissemination of knowledge-intensive farming practices. Agricultural Water Management, 96, 1491-1501. doi:10.1016/j.agwat.2009.06.022

[8] Dobermann, A. (2004) A critical assessment of the system of rice intensification (SRI). Agricultural Systems, 79, 261-281. doi:10.1016/S0308-521X(03)00087-8

[9] Rubinos, R.G., Jalipa, A.T. and Bayacag, P. (2007) Comparative economic study of organic and conventional rice farming in Magsaysay, Davao delsur. 10th National Convention on Statistics, EDSA Shangri-La Hotel, Davao City.

[10] Ismail, A.M., Johnson, D.E., Ella, E.S., Vergara, G.V. and Baltazar, A.M. (2012) Adaptation to flooding during emergence and seedling growth in rice and weeds, and implications for crop establishment. AoB Plants, 2012, pls019. doi:10.1093/aobpla/pls019

[11] Vermillion, D. (1999) Property rights and collective action in the devolution of irrigation system management. In: Meinzen-Dick, R., Knox, A. and di Gregorio, M., Eds., Collective Action, Property Rights and Devolution of Natural Resources Management, Food and Agriculture Development Center, Montana, 183-220.

[12] Khush, G. (1984) Terminology for rice growing environments. International Rice Research Institute, Manila.

[13] Ndiiri, J.A., Mati, B.M., Home, P.G., Odongo, B. and Uphoff, N. (2012) Comparison of water savings of paddy rice under system of rice intensification (SRI) growing rice in Mwea, Kenya. International Journal of Current Research and Review, 4, 63-73

[14] Pandian, B.J. (2010) The system of rice intensification: A unique system to produce more with less input. 28th International Rice Research Conference, 8-12 November 2010, Hanoi.

[15] Mati, B. (2012) System of rice intensification (SRI): Growing more rice while saving on water Kenya SRI manual. System of Rice Intensification website. http://sri.ciifad.cornell.edu/countries/kenya/index.html

[16] Satyanarayana, A., Thiyagarajan, T. and Uphoff, N. (2007) Opportunities for water saving with higher yield from the system of rice intensification. Irrigation Science, 25, 99-115. doi:10.1007/s00271-006-0038-8

[17] Li, X.Y., Xu, X.L. and Li, H. (2005) A socio-economic assessment of the System of Rice Intensification (SRI): A case study of Xinsheng Village, Jianyang County, Sichuan Province. Report for College of Humanities and Development, China Agricultural University, Beijing.

[18] Noltze, M., Schwarze, S. and Qaim, M. (2013) Impacts of natural resource management technologies on agricultural yield and household income: The system of rice intensification in Timor Leste. Ecological Economics, 85, 59-68. 
doi:10.1111/j.0002-9092.2004.00640.x

[19] Barrett, C.B., Moser, C.M., McHugh, O.V. and Barison, J. (2004) Better technology, better plots, or better farmers? Identifying changes in productivity and risk among Malagasy rice farmers. American Journal of Agricultural Economics, 86, 869-888. doi:10.1007/s10333-010-0235-1

[20] Ceesay, M. (2011) An opportunity for increasing factor productivity for rice cultivation in the Gambia through SRI. Paddy and Water Environment, 9, 129-135. doi:10.1016/j.njas.2010.11.006

[21] Uphoff, N. (2012) Comment to the System of Rice Intensification: Time for an empirical turn, NJAS-Wageningen Journal of Life Sciences, 57, 217-224. doi:10.1016/j.agsy.2009.01.001

[22] Tsujimoto, Y., Horie, T., Randriamihary, H., Shiraiwa, T. and Homma, K. (2009) Soil management: The key factors for higher productivity in the fields utilizing the system of rice intensification (SRI) in the central highland of Madagascar. Agricultural Systems, 100, 61-71. doi:10.1016/i.ecolecon.2012.10.009

[23] Barah, B. (2009) Economic and ecological benefits of system of rice intensification (SRI) in Tamil Nadu. Small, $5,9$.

[24] Zhao, L., Wu, L, Li, Y., Lu, X., Zhu, D. and Uphoff, N. (2009) Influence of the system of rice intensification on rice yield and nitrogen and water use efficiency with different N application rates. Experimental Agriculture, 45, 275-286. doi:10.1017/S0014479709007583

[25] Baskar, P., Siddeswaran, K., Thavaprakaash, N. and Muthukrishnan, P. (2012) Performance of nursery methods and crop geometry of rice varieties under rice low lands. Madras Agricultural Journal, 99, 563-566.
[26] Choi, J.D., Park, W.J., Park, K.W. and Lim, K.J. (2013) Feasibility of SRI methods for reduction of irrigation and NPS pollution in Korea. Paddy and Water Environment, 11, 1-8.

[27] Gujja, B. and Thiyagarajan, T., 2010. Producing more with less: exploring farm-based approaches to improve productivity and providing options to farmers in adapting to climate change. Proceedings of the Workshop on Advanced Technologies of Rice Production for Coping with Climate Change: No Regret Options for Adaptation and Mitigation and Their Potential Uptake, Los Baños, 23-25 June 2010.

[28] Africare Mali et SAC Goundam (2009) Fiche Technique pour le mede riziculture intensive (SRI) a Syste Tombouctou, Mali. Africare Mali, Bamako, and Secteur de l'Agriculture duCercle (SAC) de Goundam, DRA Tombouctou, Tombouctou, Mali. http://sri.ciifad.cornell.edu/countries/mali/extmats/Mali_S RI Fiche Technique09.pdf

[29] WWF-ICRISAT (2010) More rice for people, more water for the planet. WWF-ICRISAT, Hyderabad.

[30] http://sri.ciifad.cornell.edu/countries/zambia/extmats/Zam biaManual010107.pdf

[31] Kombe, E. (2012) The system of rice intensification (SRI) as a strategy for adapting to the effects of climate change and variability: A case study of Mkindo Irrigation Scheme in Morogoro, Tanzania, MSc. Dissertation, Sokoine University of Agriculture, Morogoro.

[32] Stoop, W. and Kassam, A. (2005) The SRI controversy: A response. Field Crops Research, 91, 357-360. doi:10.1016/j.fcr.2004.07.023 